\title{
Electric vehicles and their effects in low-voltage grids
}

\author{
J. Teuscher ${ }^{1}$, A. Götz ${ }^{1}$ and W. Schufft ${ }^{1}$ \\ ${ }^{1}$ Chair for Power Systems and High-Voltage Engineering \\ Faculty of Electrical Engineering and Information Technology \\ Chemnitz University of Technology \\ Straße der Nationen 62, 09107 Chemnitz (Germany) \\ Phone/Fax number: +0049 371 37752/+0049 371 837752, e-mail: jens.teuscher@etit.tu-chemnitz.de
}

\begin{abstract}
Currently the requirements to be met by the lowvoltage grid are increasing. In addition to the growth of the distributed power supply the starting e-mobility is the main cause for this change. This paper contains the simulation of different low-voltage grids with a high number of connected electric vehicles. One of the results is that the utilization of the distribution transformer is the limiting criterion for a high number of electric vehicles in urban low-voltage grids. The comparison between a urban and a rural grid shows that the voltage drop is the limiting criterion in rural low-voltage grids. A solution to charge a high number of electric vehicles is a controlled charging system which makes it possible to charge all vehicles at night.
\end{abstract}

\section{Key words}

Electric Vehicles, Simulation Low-voltage Grids, Power Flow Simulation, Energy Management, Smart Grids

\section{Introduction}

At the end of the 19th century the first electric vehicles driven in the streets reached a distance of less than $20 \mathrm{~km}$. This was the major drawback and after the electric starter was developed conventional vehicles boomed. However, at the end of the 20th century electric vehicles are again in the focus of research. This is caused by the development of the Li-Ion-Battery as well as the increased awareness of environmental aspects.

One topic of actual research is the connection of electric vehicles to the grid. One possibility is to exchange the battery and charge it at some main station like a petrol station. This option requires a connection to the mediumvoltage grid and allows to power a high number of electric vehicles. The second possibility is decentralized charging in the low-voltage grids. This is a big challenge, due to the fact that low-voltage grids were not dimensioned for this high power flow. This paper describes the effects of charging a high number of electric vehicles in different low-voltage grids.

\section{Electric Vehicles in Germany}

In 2009 the German government published the national planning for electric vehicles. Among other things this directive includes the aim to have one million electric vehicles in 2020 and five million electric vehicles 2030 in Germany [1].

These aims are not legal requirements but merely a vision. It depends on many factors whether these goals can be achieved or even exceeded. In addition to the costs of a nationwide charging infrastructure system, range extension, durability and acceptance in the population will be challenges.

The use of electric vehicles is currently tested in some pilot projects. First experiences have been gathered with the electric vehicle as well as with the battery charge. These are some practical approaches to combine the two major industrial sectors of energy supply and automobile industry but also to raise people's awareness of the issue. Unfortunately, financial assistance for the purchase of electric vehicles which is common in France is not envisaged by the federal government in Germany at the moment.

Research reveals that the average daily car route is around $40 \mathrm{~km}$ [2]. If an electric vehicle needs $20 \mathrm{kWh} / 100 \mathrm{~km}$, it needs $8 \mathrm{kWh}$ every day. This means an electricity consumption of approx. $2 \mathrm{TWh} /$ year for one million electric vehicles which corresponds to only $0.3 \%$ of the total electricity consumption in Germany in 2007. (600 TWh) [3].

A more relevant aspect is the connection and the charging. It seems possible, that every electric vehicle can be charged with a power of $20 \mathrm{~kW}$. Due the most protections of low-voltage sockets in the households, it is only practicably to charge with less than $10 \mathrm{~kW}$. One million electric vehicles require $10 \mathrm{MW}$. The worst case would be, if every electric vehicle would charge its batteries at 
the same time. At the present a reserve capacity of $10 \mathrm{GW}$ is available in German power plants. [3] A supply of this power is possible with the existing power plants without extension for a million electric vehicles. The sufficient reserve of power plants does not mean that the distribution grid can supply this high performance connection. The main challenge is to supply these loads in the low-voltage grids locally. This fact and a later increase of the number of electric vehicles make it essential to develop an energy management.

\section{Simulation of Low-voltage Grids}

The simulated low-voltage grids are based on real grids in Germany. There are two different kinds, the urban and the rural grid. The urban grid supplies a lot of households in a small area while the rural grid is the complete opposite characterized by long lines. Table I shows a comparison between these two kinds of grids. The simulation of such different grids is important because it shows the individual requirements of these kinds of grids.

Table I: Comparison between different low-voltage grids

\begin{tabular}{|l|c|c|}
\hline & URBAN GRID & RURAL GRID \\
\hline $\begin{array}{l}\text { Distribution } \\
\text { Transformer } \mathrm{S}_{\mathrm{r}}\end{array}$ & $630 \mathrm{kVA}$ & $250 \mathrm{kVA}$ \\
\hline Max. length of line & $200 \mathrm{~m}$ & $1400 \mathrm{~m}$ \\
\hline Powered households & 860 & 230 \\
\hline
\end{tabular}

Another special challenge is the simulation of the load curve in the low-voltage grids. The majority of consumers in the simulated grids are households. This is a basic boundary condition because industrial consumers modify the common load curve essentially. Mostly industrial consumers are concentrated in areas with own low-voltage grids. So this boundary condition is well-founded.

The households load curve is based on measured time courses. Every household has a fluctuating load curve with individual peaks. The result of summarizing a lot of households is the common load curve with the peaks in midday and evening and the minimum loads at night.

The starting point for the simulation of the load curve is the real load curve at the medium-voltage transformer station. The quarter-hourly values are known over a period of one year. The power calculation program ELEKTRA is a static calculation program which calculates only for one moment. So it is very time-consuming to simulate one year. It is more useful to select individual days of one year and calculate them. The selection follows in a similar manner to the VDEW-curves, i.e. the week is divided into weekdays, Saturday and Sunday. These three days have their own characteristic load profiles. Differences in the individual business days are neglected. Furthermore, these days are assigned to the seasons. It is sufficient to consider only the maximum values. These are the winter days because of their high energy demand.

The power flow simulation without electric vehicles shows the actual situation of the low-voltage grids. The distribution transformer has a utilization ratio by $50 \%$ -
$60 \%$ in this scenario, shown in figure 1. This is also included in the dimensioning guidelines for low-voltage grids. [4] At night the distribution transformer has a utilization ratio of less than $20 \%$. This shows the available capacity for charging electric vehicles. It must be pointed out that apart from the utilization of the distribution transformer the voltage drop and the line utilization are important for this examination.

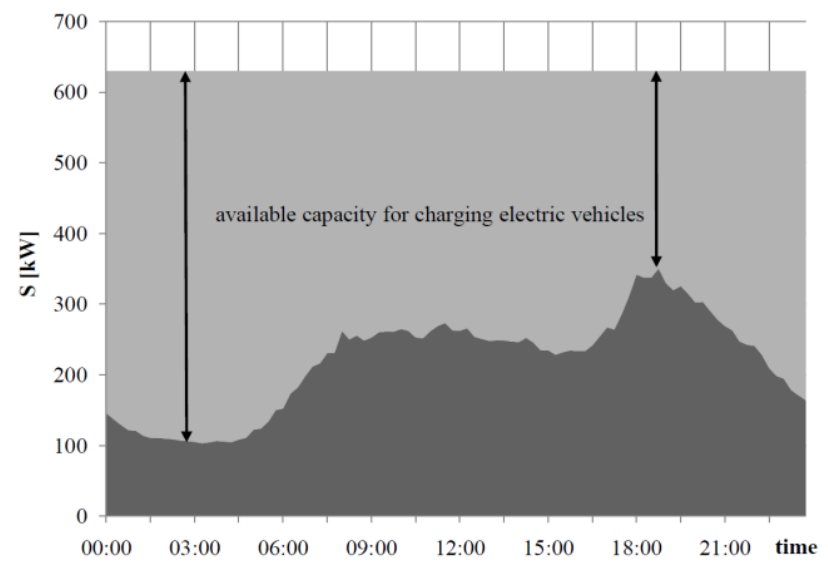

Fig.1: Utilization of the distribution transformer

\section{Charging of Electric Vehicles}

In addition to the load curve of the consumers the charging curve of the electric vehicles is the next step. It is not probable that every electric vehicle has the same daily distance and needs an energy consumption of $8 \mathrm{kWh}$ per day. While the majority of the electric vehicles will need less energy per day a minority of them will need a lot more energy. This relation is described by a chi-square distribution function (1) with an average energy consumption of $8 \mathrm{kWh}$.

$$
f_{n} \boldsymbol{C}=\frac{x^{\frac{n}{2}-1} \cdot e^{-\frac{x}{2}}}{2^{\frac{n}{2}} \cdot \Gamma\left(\frac{n}{2}\right)}
$$

Figure 2 shows this distribution for charging 100 electric vehicles. At the beginning all electric vehicles charging at the same time with $10 \mathrm{~kW}$.

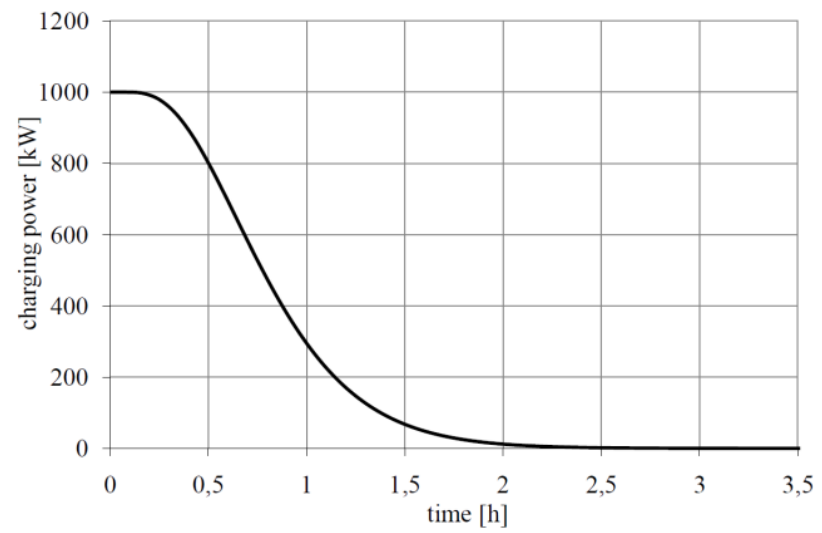

Fig. 2: Chi-Square distribution for charging $100 \mathrm{EV}$ 's

Most of the electric vehicles are charged in the first hour. This based on the short distances of the most vehicles. 
Only a few electric vehicles need more than half an hour for charging. But the sum of the energy consumption is independent of individual routes.

Available charging unit for lithium-ion batteries serve as for the charging curve of an electric vehicle. The maximal charging current is $16 \mathrm{~A}$ and based on most usual protection value of the low-voltage sockets. Furthermore, the charging time corresponds to the daily energy consumption of $8 \mathrm{kWh}$. It should be noted that the efficiency of the charging system and the lithium-ion battery is nearly $90 \%$, i.e. $10 \%$ more energy has to be supplied. Figure 3 shows the resulting charging curve used in the simulation of the low-voltage grid as an additional consumer and simulating an electric vehicle.

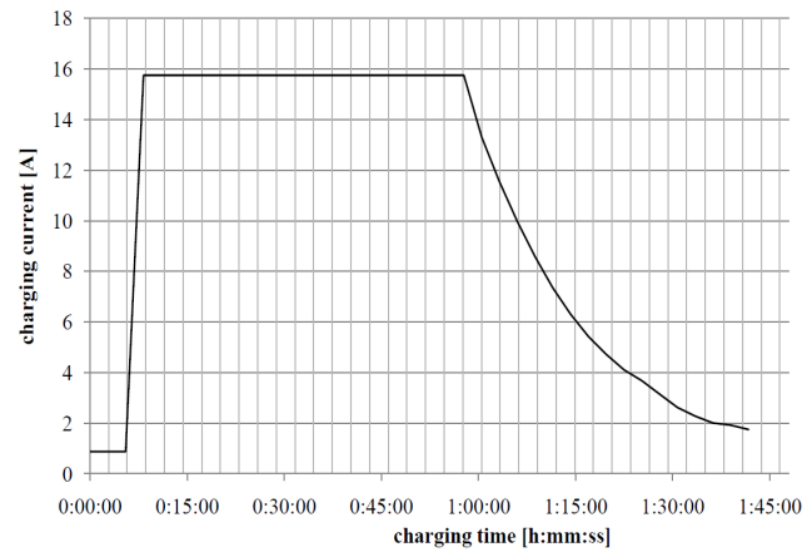

Fig. 3: Charging of an electric vehicle

\section{Results}

\section{A. Urban Low-voltage Grids}

The considered urban low-voltage grid supplies 860 households with electricity. It can be approximately assumed that every second household has one vehicle. An electrification of individual transport of $100 \%$ would mean about 430 electric vehicles to be charged in this low voltage grid.

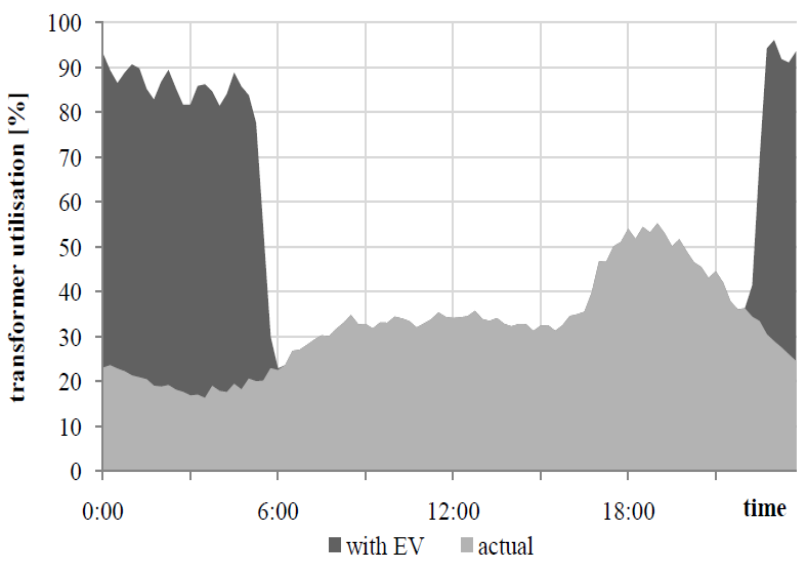

Fig. 3. Utilization of the distribution transformer in different cases

The power flow simulation shows that the utilization of the distribution transformer is the limiting criterion for urban low-voltage grids. Charging 32 electric vehicles at the same time would break the limit of the transformer. Based on the minor length and the major cross section of the lines voltage drop and line utilization are not the critical facts.

It is possible to charge 430 electric vehicles over night completely with a controlled charging which lead to a rate of electrification by $100 \%$ of all vehicles. Figure 3 shows a comparison between this scenario and the present situation without electric vehicles.

The controlled charging (see figure 4) starts at $10 \mathrm{pm}$ and ends at 6 am. Every five minutes, six electric vehicles start the charging. After one hour the charging is finished on average. This procedure is only one possibility to control the charging. Nevertheless, it is necessary to charge a high number of electric vehicles.

The small peaks and valleys in the load curve for electric vehicles are based on the different of rise and fall times in the progress of charge. (see figure 3 )

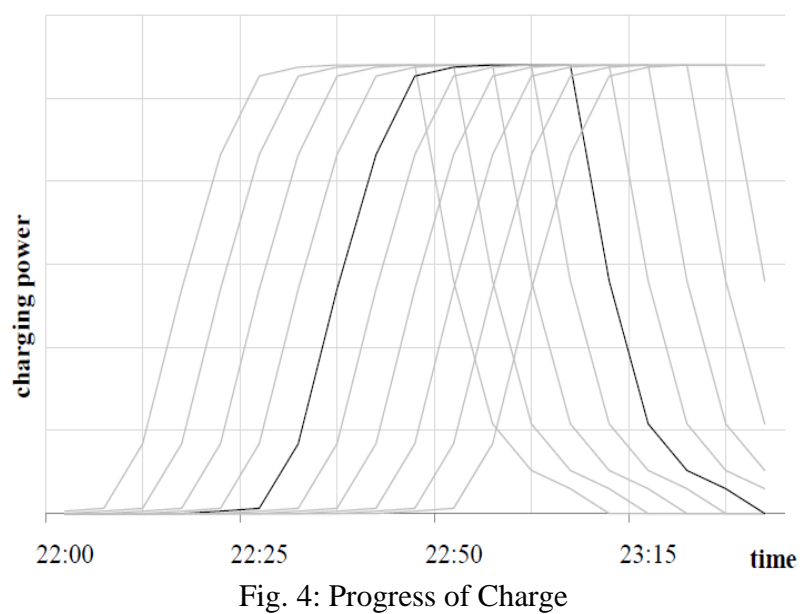

It is possible to charge all vehicles in the area of the rural grid with the controlled charging. This scenario will probably not occur in the near future but it shows the possibility to load 430 electric vehicles in a low-voltage grid. By exchanging the local distribution transformer or a second parallel transformer it is possible to reach higher capacity. Unfortunately, the maximal utilization of the lines forbids a significant increasing of this capacity.

Furthermore, it should be noted that the lines have a high utilization in this case. The distances between parallel lines are close in urban grids and so the lines mutually heat up. Thus, it would be better to use the whole day for charging. The challenge here is that many electric vehicles are not connected to a charging station during the day. Therefore it is possible to reduce the peaks at night and to prevent such a high utilization of the distribution transformer and the lines. The charging during the day is an opportunity to use decentralized renewable energy systems, i.e. photovoltaic energy, as well as to leave the utilization of the distribution transformer during the day unchanged. 


\section{B. Rural Low-voltage Grids}

The power flow simulation in rural grids shows that the critical point is not the distribution transformer utilization. The permissible voltage drop determines how many electric vehicles can be connected. There will be a high voltage drop if an electric vehicle is charged at the end of a long line. The standard DIN EN 50160 limited the voltage drop in low-voltage grids to $\pm 10 \%$. [5] Table 2 gives an overview on the relation between the line length and the number of regularly connected electric vehicles. An electric vehicle can be called regularly connected if the voltage at the connecting point does not exceed the described limits.

Table II: Relation between electric vehicles and line length

\begin{tabular}{|c|c|}
\hline $\begin{array}{c}\text { NO. OF REGULARLY CONNECTED } \\
\text { ELECTRIC VEHICLES }\end{array}$ & $\begin{array}{c}\text { LINE } \\
\text { LENGTH [m] }\end{array}$ \\
\hline 8 & 300 \\
\hline 6 & 350 \\
\hline 4 & 380 \\
\hline 3 & 650 \\
\hline 2 & 700 \\
\hline
\end{tabular}

The number of regularly connected electric vehicles depends on the grid arrangement. In rural low-voltage grids the lines are often longer than 700 meters. So a controlled charging is essential to charge a high number of electric vehicles.

A simple way is to use the same controlled charging system as used in the urban grid with the differences of only two electric vehicles starting at the same time to be charged.

Another way to guarantee the voltage stability is a controllable local distribution transformer which is currently tested in pilot experiments and forms the first practical implementation of a smart grid. [6] It should be noted, that the grid arrangement in rural low-voltage grids is not the same like an urban low-voltage grid. Rural grids consist of distribution transformers with a small nominal power and lines with mostly a small cross section. Thus high utilization of a rural grid cannot supply the same number of electric vehicles as an urban low-voltage grid. However, the number of vehicles in the most rural areas is not as high as in an urban area. Therefore, the minor dimensioning is not an essential disadvantage concerning the charging of electric vehicles.
It depends on the different rural low-voltage grids, which of these described options fulfil the particular requirements. It is impossible to make a general statement because of the significant differences in the grid arrangement of rural low-voltage grids.

\section{Conclusion}

The charging of a high number of electric vehicles in urban low-voltage grids is possible with controlled charging. The critical point in the urban grid is the distribution transformer. There is no need to modify the grid arrangement.

The critical point in the rural low-voltage grid is the voltage drop. Controlled charging is also possible, although more difficult.

The study shows that electric vehicles would be the first parts of a smart grid. With the increase of the number of electric vehicles the requirement of communication systems grows.

The next step involves a verification of the simulated lowvoltage grids. At the moment starts a measuring on the rural distribution transformer. The aim is to develop a realistic simulation system.

Furthermore, the focus is on the development of an energy management system that includes not only the necessary charging management. There is also the aim of a high integration of renewable energy in the low-voltage grids. The losses will be the optimization criterion because over $75 \%$ of all losses are based on the low-voltage grids. With the increasing requirements on these grids the losses will also increase without an energy management system.

\section{References}

[1] Nationaler Entwicklungsplan Elektromobilität http://www.bmwi.de/Dateien/BMWi/PDF/nationalerentwicklungsplan-elektromobilitaet-der-

bundesregierung,property $=$ pdf, bereich $=$ bmwi, sprache $=\mathrm{de}, \mathrm{rwb}=\mathrm{tr}$ ue.pdf [06.01.2011]

[2] De La Fuente Layos, Mobilität im Personenverkehr in

Europa, eurostat, Luxembourg (2007)

[3] BDEW, Energiemarkt Deutschland, VWEW Energieverlag

GmbH, Frankfurt a. M. (2009)

[4] Schmidt/Hempel, Mittelspannungsanlagen -

Planung / Errichtung / Prüfung/Betrieb, HUSSMEDIEN

$\mathrm{GmbH}$, Berlin (2007)

[5] DIN, EN 50160 - Voltage characteristics of electricity supplied by public distribution networks; German version prEN 50160:2008, Berlin (2008)

[6] E.ON AVACON AG, Regelbarer Ortsnetztrafo, 2010, http://www.eon-avacon.com/Cms/Default.aspx $? i d=6737 \& \mathrm{ch}=9$ [29.11.2010] 